\title{
Rock Physics, Geomechanics and Rock Properties in Shales - Where are the Links?
}

\author{
D.N. Dewhurst CSIRO Petroleum, Australia
}

A.F. Siggins CSIRO Petroleum, Australia

U. Kuila Colorado School of Mines, USA

M.B. Clennell CSIRO Petroleum, Australia

M.D. Raven CSIRO Land and Water, Australia

H.M. Nordgard-Bolas StatoilHydro Research Centre, Norway

\begin{abstract}
Understanding shale behaviour is of increasing importance to the petroleum industry and also impacts on engineering issues such as landslides and hazardous waste disposal. Few data are currently available regarding geomechanical, petrophysical and dynamic elastic properties of shales that have been properly preserved and tested under controlled pore pressure conditions. The research detailed here involves triaxial testing of shales to determine failure envelopes, with ultrasonic measurements taken during the application of differential stress through to failure. Empirical relationships are then derived between the geomechanical properties and more easily (or regularly) measured physical and petrophysical properties such as porosity, clay content, cation exchange capacity and dielectric properties. The dynamic elastic properties of shales and their anisotropy are shown to be significantly impacted by maximum principal stress orientation with respect to microfabric and microfracture orientation.
\end{abstract}

\section{Introduction}

Shale properties are important for the petroleum industry in relation to seal evaluation and wellbore stability for example. In recent years, quite a few studies have looked at the influence of diagenesis, compaction and lithology on geomechanical properties of shales (Marsden et al., 1992; Horsrud et al., 1998; Nygard and Gutierrez, 2002; Dewhurst and Hennig, 2003; Nygard et al., 2004). Shale dynamic elastic properties have been shown to be sensitive to factors such as composition, organic content, pore pressure and stress history (Vernik and Liu, 1997). However, shale cores are rarely recovered or preserved to prevent desiccation and fracturing. Consequently, little reliable information is available concerning physical properties and geomechanical behaviour of these rocks. Some of the aforementioned shortcomings (lack of core and/or preservation) have been overcome through preservation of selected shale cores for this project from the Bass, Norwegian Sea, Carnarvon and Officer basins. Brief objectives of the study can be summarised as follows:

- Characterisation of preserved shales with regard to geomechanical, petrophysical, dynamic elastic and physical properties.

- Correlate laboratory-measured geomechanical properties of well-characterised shales with petrophysical and physical properties.

- Evaluate the rock physics response with respect to stress field and fabric orientation.

\section{Sample characterisation}

The shales from the four aforementioned basins range in age from Proterozoic to Cretaceous/Tertiary. The Norwegian shale (Figure 1) is a kaolinite and quartz-rich, fine grained tight, laminated shale. Generally, it is clay matrix supported, even in silt-rich laminations. It has a porosity of $\sim 15 \%$, with a low specific surface area $\left(\mathrm{SSA}=8 \mathrm{~m}^{2} / \mathrm{g}\right)$, moderate clay fraction $(40 \%)$ and high clay content $(65 \%)$. 

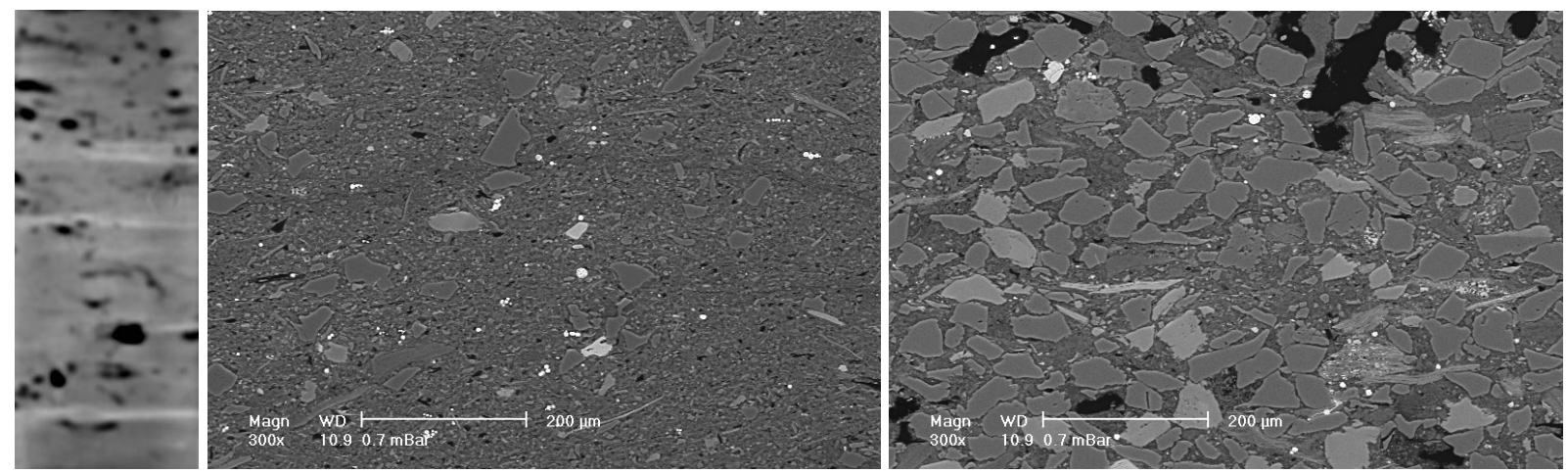

Figure 1 CT scan of a $76 \mathrm{~mm}$ by $38 \mathrm{~mm}$ core plug (left) and backscattered scanning electron microscopy (BSEM) images of the Norwegian shale. The negative CT image shows silty laminations (bright grey) and pyrite (black), with thicker, dark grey laminations. The SEM images are from clay-rich (centre) and silt-rich (right) laminations and have the same scale
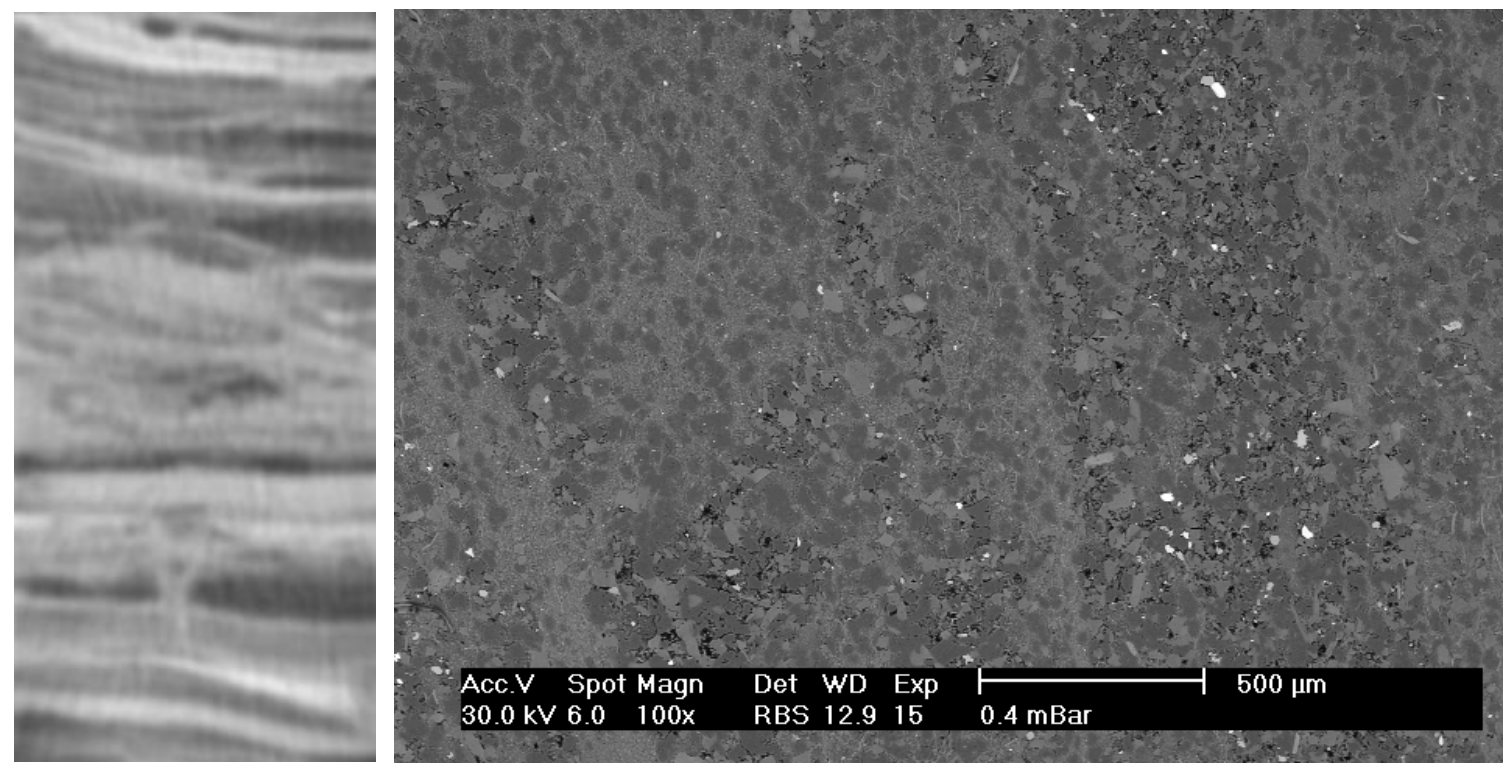

Figure 2 CT scan of a $76 \mathrm{~mm}$ by $38 \mathrm{~mm}$ core plug (left) and a BSEM image of the Officer Basin shale. The CT scan shows clay-rich laminations (bright grey) and siltier bands (dark). The BSEM image shows a laminated shale with porosity preservation in quartz and orthoclase rich layers (right side of BSEM image), while little porosity is evident in illite and dolomite rich layers (left side of BSEM image)

The suite of Officer Basin shales (Figure 2) are illite-rich with significant quartzo-feldspathic components; some have alternating coarse and fine grained laminations. They have porosities of $\sim 6-13 \%$, with moderate SSA $\left(10-32 \mathrm{~m}^{2} / \mathrm{g}\right)$, clay fractions of $\sim 25-50 \%$ and clay contents of $30-60 \%$.

The Bass Basin shales are quite silty and are dominated by quartz and kaolinite. They are laminated and also contain coaly streaks. They have low porosity (4-6\%), low SSA $\left(1-3 \mathrm{~m}^{2} / \mathrm{g}\right)$, with clay fractions of $\sim 25 \%$ and clay contents $\sim 40 \%$.

The Carnarvon Basin shale, the Muderong shale, is dominated by mixed layer illite-smectite and quartz, with significant amounts of kaolinite (Figure 3). It has a porosity of $\sim 18 \%$, SSA of $\sim 30 \mathrm{~m}^{2} / \mathrm{g}$, clay fraction of $\sim 45 \%$ and clay content of $\sim 65 \%$. This shale has been studied extensively for physical, geomechanical and rock physics properties (Dewhurst et al., 2002; Dewhurst and Hennig, 2003; Dewhurst and Siggins, 2006). 

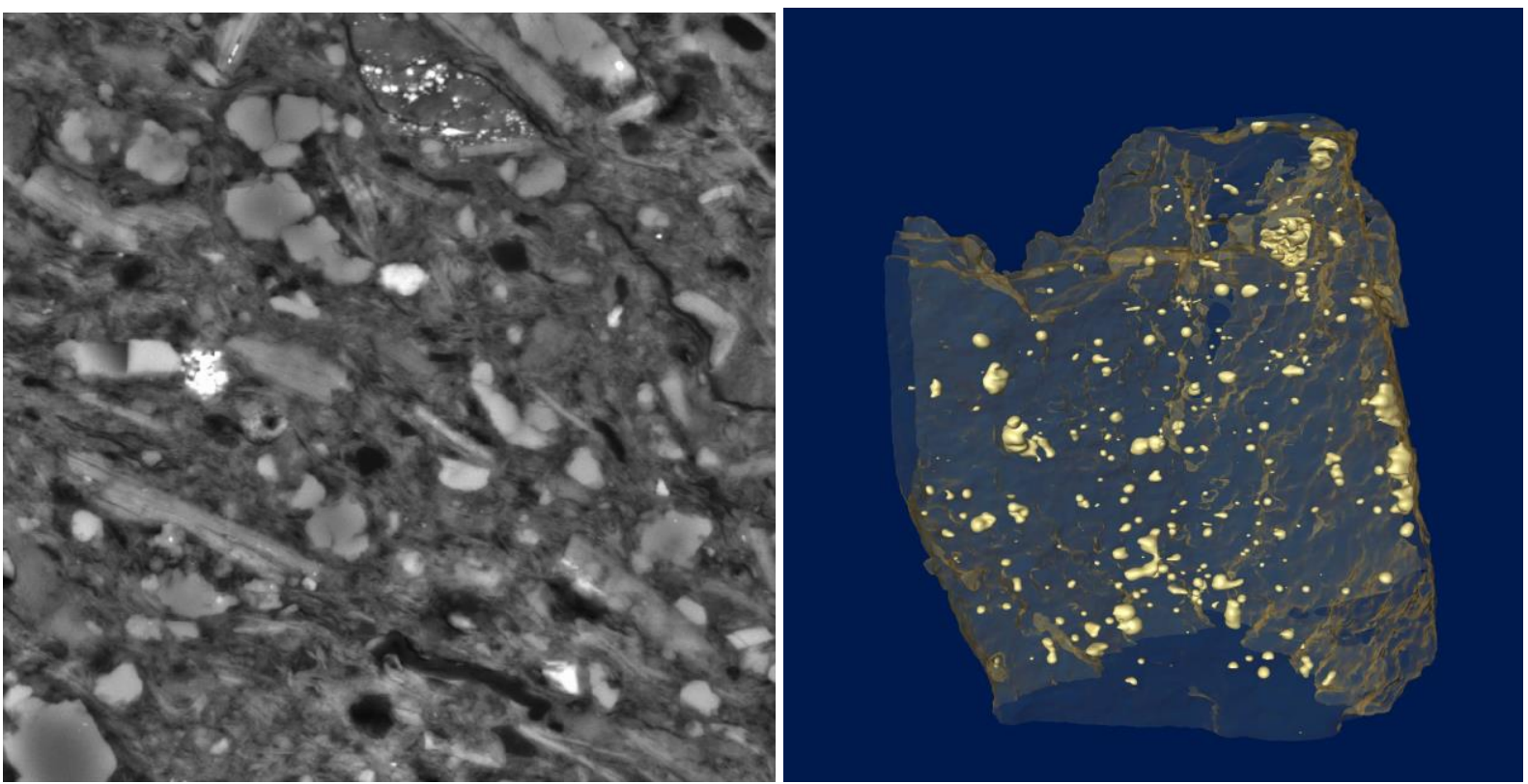

Figure 3 BSEM image of the Muderong shale (left), showing a strongly aligned fabric normal to compaction, although some clay aggregates are oblique to this in places. Image is $\mathbf{1 0 0} \boldsymbol{\mu m}$ across. X-ray microscope tomogram of the Muderong shale (right) showing pyrite clusters. The shale piece is $\sim 1 \mathrm{~mm}$ across

These shale suites were also characterised using petrophysical techniques, including nuclear magnetic resonance and dielectric testing. Examples of the NMR data and full details of the dielectric method can be found in (Clennell et al., 2006). The motives behind our dielectric tests were its previous use for clay typing and strength estimation (Steiger and Leung, 1988; Ingram and Urai, 1999). The dielectric measurement system is built around an Agilent ENA-E5070B network analyser and uses a simple terminated coaxial probe against which the sample is pressed during measurement. The electromagnetic signal travelling to the probe is reflected partially at the termination and the reflection coefficients depend on the conductivity, permittivity and magnetic permeability of the volume of material surrounding the tip region. The region of investigation of the probe is small and the signal is very sensitive to the exact placement of the probe against the shale sample. We found that maximum repeatability was achieved by grinding away surface contamination from the preserved shale core, placing a water drop on the smooth surface, and placing this against the fixed probe with a firm and constant pressure in such a way that any air was completely excluded and the water itself expelled from the tip region. Even so, the repeatability of measurements on solid samples was not very good compared with the specification of the analyser and the excellent repeatability obtained on standard liquids where probe positioning and pressure is not important. We therefore made at least five repeats at each measurement point.

The results of the dielectric probe measurements are summarised in Figure 4. The real dielectric constant varies from around 10-30 at $3 \mathrm{GHz}$, and increases to values from 50-500 at $1 \mathrm{MHz}$. The imaginary part or dielectric loss plots as an almost straight line in log-log space, the slope and values of which vary in proportion to the conductivity, with the most conductive (least resistive) shales, i.e. Norwegian and Muderong, having the highest loss. The Bass Basin shales have the lowest water content and are highly resistive, giving low $\mathrm{DC}$ at $1 \mathrm{GHz}$, little dispersion towards lower frequencies and the lowest loss. The higher water content Officer red shale from $390 \mathrm{~m}$ depth has substantially higher loss and DC than the more compacted sample from $604 \mathrm{~m}$. The Norwegian shale has a high DC at $1 \mathrm{GHz}$, the highest loss, and very strong frequency dispersion. It is surprising that the DC of Norwegian shale is higher for frequencies $>30$ $\mathrm{MHz}$ than the Muderong shale and is also more dispersive than the Muderong, as the latter has a higher surface area (due to the presence of expandable clays) and approximately twice the water content. We believe that the extreme $\mathrm{MHz}$ frequency dispersion of the dielectric properties of the kaolinitic Norwegian shale may be due to high conductivity of pyrite at the surface of the core plug measured (see CT scan in Figure 1). 


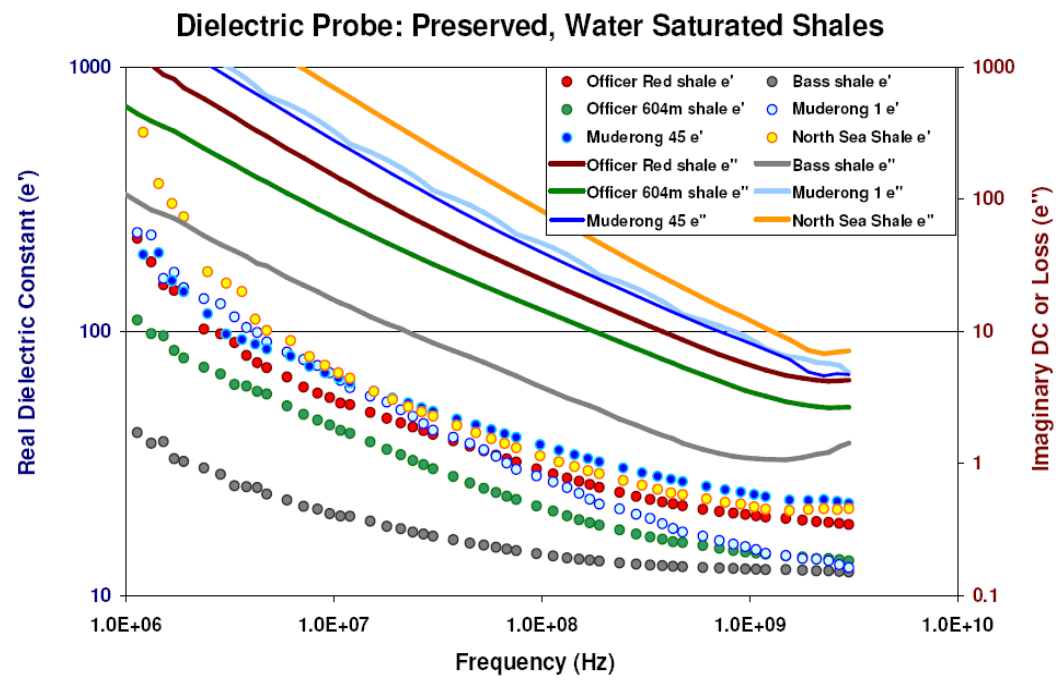

Figure 4 Dielectric properties of shales in the MHz to GHz range. Dots show the real dielectric constant (DC) and the lines the dielectric loss

\section{Rock mechanics and rock physics methodology}

Full details of the testing equipment used in these tests are contained in Dewhurst and Siggins (2006). Consolidated undrained (CU) multi-stage triaxial tests have been performed on shale core plugs at successively increasing confining pressures to determine a failure envelope (Figure 5). For CU tests, samples are consolidated isotropically in a drained state to a set level of confining pressure with drainage at both ends to ensure pore pressure equilibration throughout the sample. As saturation may be affected by core recovery, a pore pressure of $5 \mathrm{MPa}$ was applied during the isotropic consolidation stage to ensure full sample saturation. Having achieved the desired consolidation state, the pore pressure lines were closed and the sample loaded axially in an undrained state at low strain rate $\left(1.22 \times 10^{-7} \mathrm{~s}^{-1}\right)$, to ensure even pore pressure change through the sample, while stress, strain and pore pressure changes were monitored. Deformation in each stage was allowed to reach within $\sim 10 \%$ of peak strength before unloading, except for the last stage where samples were taken through to failure. Performing multi-stage tests in this manner rather than using single stage triaxial tests involves a trade-off. The single stage test (Figure 5, left) allows for samples to be deformed through to residual strength and is the standard method for derivation of failure envelopes. However, heterogeneity between core plugs can introduce serious variability in rock physics measurements. Running multi-stage tests (Figure 5, right) is advantageous when sample material is scarce and homogeneity is required for rock physics measurements, but the trade-off is that such tests may fatigue a single core plug and perhaps make it appear weaker than it actually is.

Typically, measurements for velocity anisotropy (i.e. velocities normal to and parallel to bedding) in shales required the use of multiple core plugs thus further increasing time required for such tests to be performed. We designed an experimental configuration that allows the full elastic tensor to be calculated from a single core assuming that the shale is a transversely isotropic (TI) medium (Dewhurst and Siggins, 2006). P-wave and S-wave velocities can be measured through end platens that house $1 \mathrm{MHz}, \mathrm{PZT}-5 \mathrm{H}$ piezo-ceramic Pwave and S-wave elements to measure velocity down the core axis. In addition, orthogonal P- and S-wave transducers are located on the membrane to measure velocity across the core diameter. A post on the aluminium shear-wave transducer housing penetrates through the Viton membrane to rest against the sample and improves identification of S-wave arrivals. Finally, a pair of P-wave elements (set in cylindrical wedges of acrylic resin and directly facing one another) transmit and receive pulses at $45^{\circ}$ to the core axis (Dewhurst and Siggins, 2006) for complete description). This configuration of wedges was necessary in order to make all necessary measurements for the determination of the stiffness tensor on a single core with the shale principal axes aligned with the cell rather than using a number of cores cut at varying angles to the principal axes. Calibrations of the array were performed using aluminium, acrylic resin and phenolite cylinders of similar geometry to the test samples. 

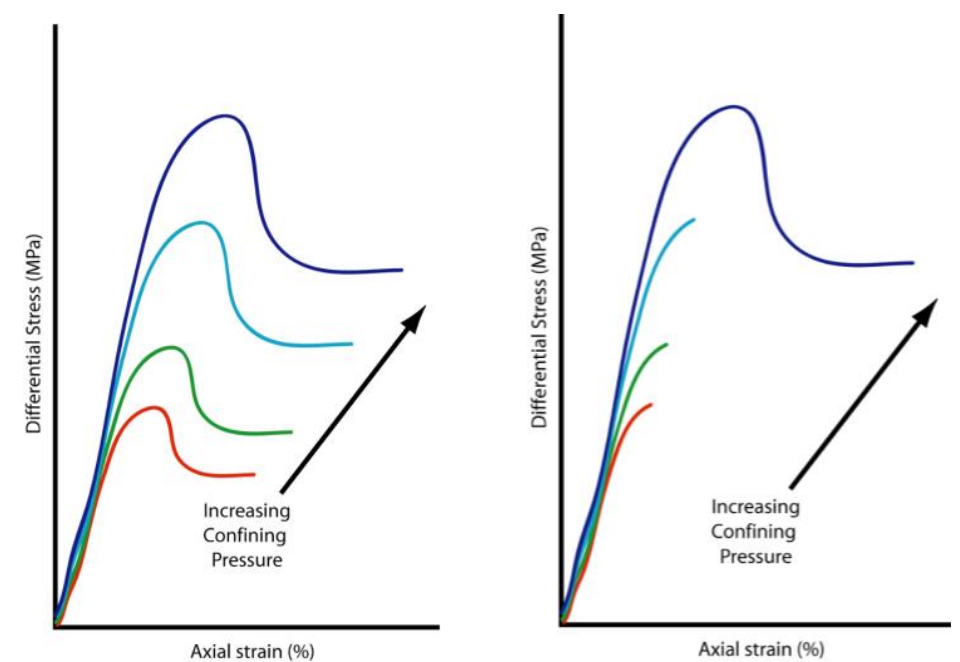

Figure 5 Schematic stress-strain curves for single stage (left) and multi-stage (right) triaxial tests. Ultrasonic measurements are made at successively increasing increments of differential stress in the multi-stage test until just before unloading
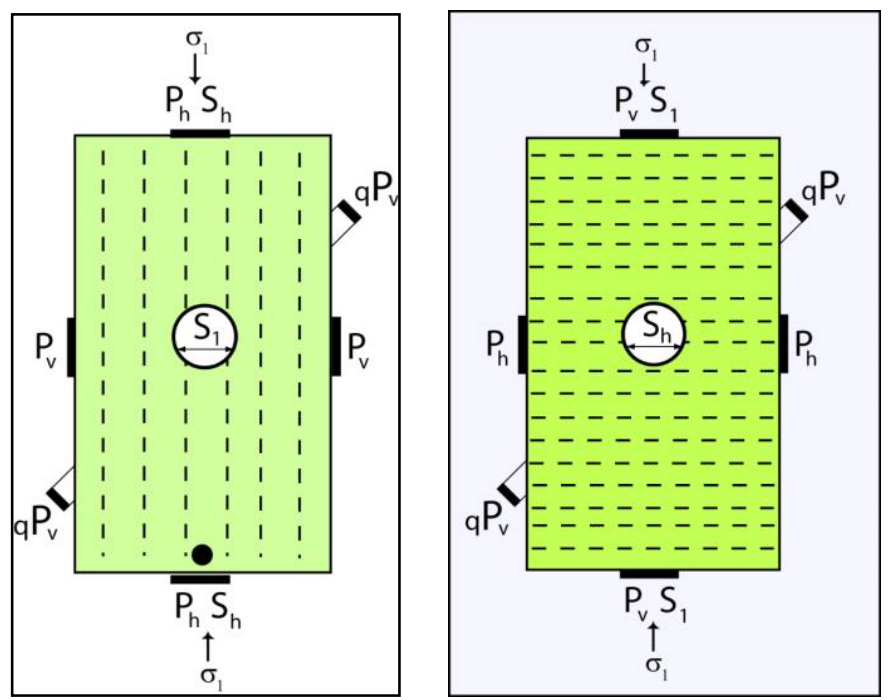

Figure 6 Schematic of core plugs cut parallel (left) and normal (right) to bedding and associated rock physics nomenclature

Ultrasonic tests were run on core plugs cut both parallel and normal to bedding (Figure 6). The Norwegian shale discussed below was plugged parallel to bedding. The Officer Basin shale discussed below was plugged normal to bedding. Ultrasonic parameters measured during the shale triaxial testing programme included $V_{p v}, V_{p h}, V_{s l}, V_{s h}$ and quasi-P $\left(q V_{p 45}\right)$ at nominal centre frequencies of $0.6-1.0 \mathrm{MHz}$ (for P-waves) to $0.2-0.4 \mathrm{MHz}$ (for $\mathrm{S}$-waves). Arrival time picks were based on first breaks estimated from approximately $1 \%$ of the first peak amplitude. Uncertainties were $\pm 0.1 \mu$-seconds for P-wave arrival times and $\pm 0.2 \mu$-seconds for S-waves, corresponding to velocity errors of $\pm 0.4 \%$. Picking errors are reduced as effective stress increases, especially for S-waves. Errors in elastic constants are generally $<1 \%$, with the exception of $c_{13}$ where errors are estimated as $\sim 2 \%$, while errors in the anisotropy parameters are higher due to the use of ratios of elastic constants. Here, errors in $\varepsilon$ and $\gamma$ may range up to $2 \%$, while $\delta$ has the least accuracy, with errors of typically $\pm 13 \%$. 


\section{Results}

\subsection{Geomechanical correlations}

The rationale behind this work was to evaluate methods of predicting geomechanical properties of shales from other more easily measured physical properties and eventually from properties that can be extracted from wireline logs (LWD/MWD). To that end, the shales we have examined so far have been thoroughly characterised in terms of composition, microfabric, specific surface area, cation exchange capacity, seal capacity, rock physics response, Nuclear Magnetic Resonance spectra and dielectric properties as well as their geomechanical properties such as cohesive strength and friction coefficient. In this study, some of these properties have been compared statistically to the geomechanical properties using simple single variable comparisons. Many different comparisons were made, some with reasonable correlation coefficients and some with extremely poor correlation coefficients. These latter relationships will generally not be shown in any detail, although it will be noted in the text which properties correlated poorly with the geomechanical properties. Correlation coefficients are moderate as might be expected with experimental data on rocks with a wide range of compositions, geological histories, provenance and age.

One parameter that has regularly been used in terms of estimating rock strength properties in situ is sonic or ultrasonic velocity. However, neither $\mathrm{V}_{\mathrm{pv}}$ nor $\mathrm{V}_{\mathrm{s} 1}$ correlate well $\left(\mathrm{R}^{2} \sim 0.45\right)$ with cohesive strength. Other factors affect velocity in shales, including stress state, stress history, porosity, lithology, organic content, microstructure and physicochemical interactions with pore fluids (Holt et al., 1991; Vernik and Liu, 1997). As the main variables between these shales that influence velocity are porosity and lithology, it was decided to use P-wave impedance normalised to lithology (using both clay fraction and clay content). This improved the correlations as follows (Figure 7):

$$
\begin{array}{ll}
C=-5.78+\left(7.77 \times 10^{-5}\right) Z_{p c c} & \left(\mathrm{R}^{2}=0.66\right) \\
C=-2.10+\left(2.99 \times 10^{-5}\right) Z_{p c f} & \left(\mathrm{R}^{2}=0.70\right)
\end{array}
$$

where $\mathrm{C}$ is cohesive strength in $\mathrm{MPa}$, while $\mathrm{Z}_{\mathrm{pcc}}$ and $\mathrm{Z}_{\mathrm{pcf}}$ are $\mathrm{P}$-wave impedances in $\mathrm{kg} / \mathrm{m}^{2} / \mathrm{sec}$ normalised to clay content and clay fraction respectively.
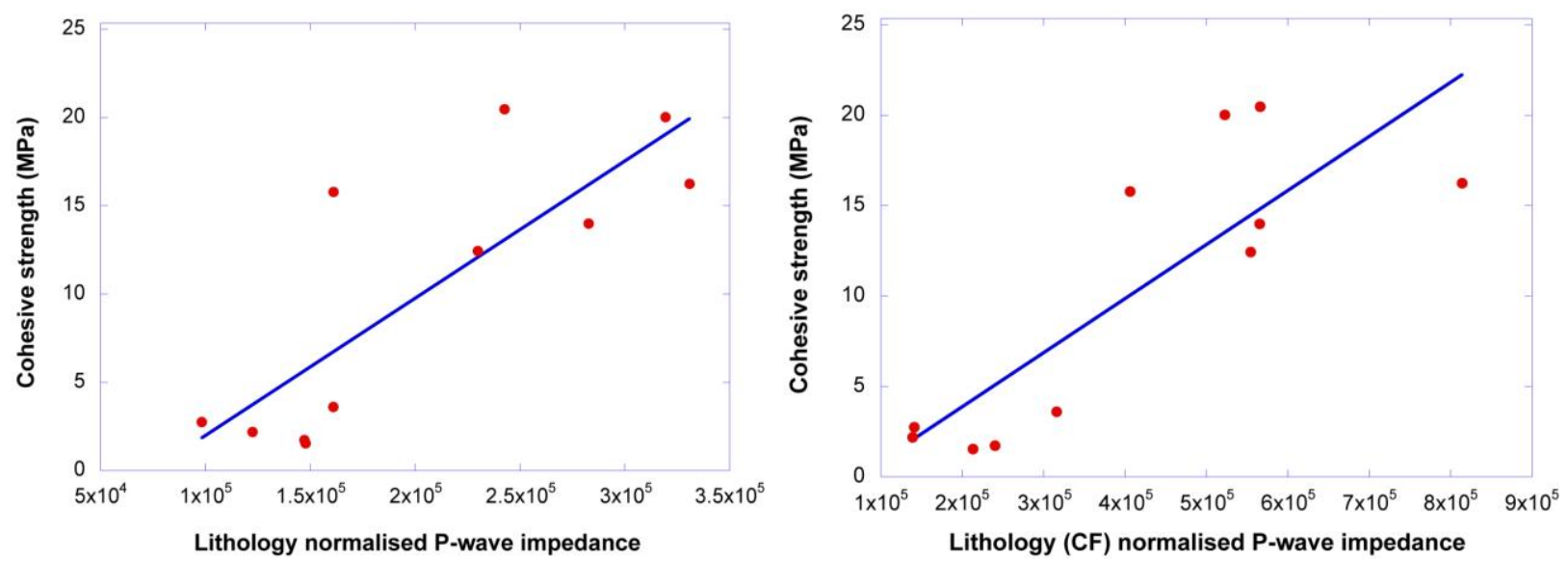

Figure 7 Correlations between P-wave impedance normalised to clay content (left) or clay fraction (right) and cohesive strength for shales from the Bass, Norwegian Sea, Officer and Carvarvon basins. Fits for regression lines shown

The presence of clays is known to significantly affect rock strength and compressibility, with both composition (clay content) and grain size (clay fraction (Aplin et al., 1995)) previously noted as important controls. 

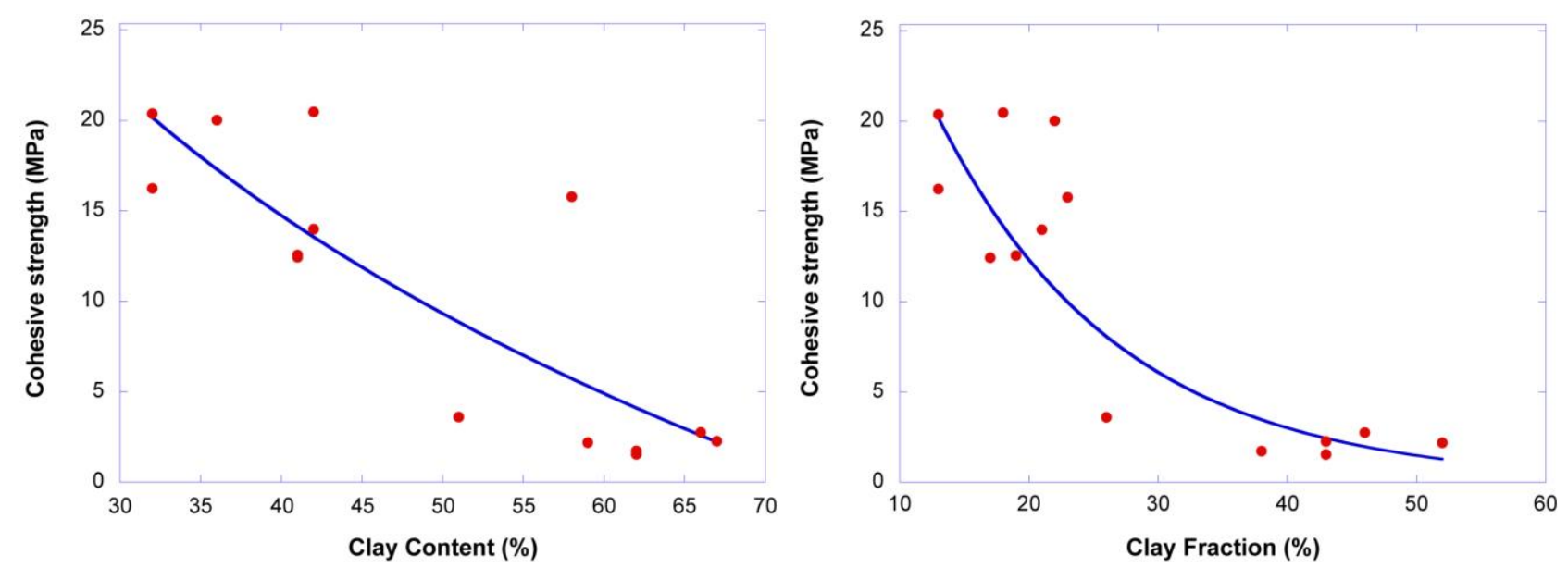

Figure 8 Plot of clay content from X-Ray Diffraction analysis (left) and clay fraction (grain size, from centrifuging, right) against measured cohesive strength for shales from the Bass, Norwegian Sea, Officer and Carvarvon basins

Clay content affects cohesive strength broadly speaking (Figure 8, left), decreasing strength with increasing clay content as might be expected. A couple of outliers from the Officer Basin shales lie well off the regression line, somewhat detracting from the correlation. Linear, exponential and logarithmic fits were made to these data although the exponential fit alone is shown:

$$
C=219.6 e^{-0.07 C C} \quad\left(\mathrm{R}^{2}=0.65\right)
$$

where CC is clay content as a percentage. The exponential fit was preferred in this case, even though it has a lower correlation coefficient, as it was more logical physically, in that the linear and logarithmic fits tend to zero cohesive strength at clay contents $>70 \%$. Similar relationships can also be found for clay fraction $(<2 \mu \mathrm{m}$ fraction) in the rock; this factor can govern rock strength (and other properties such as permeability and wave velocity) when rigid grains interlock as opposed to float in a clay matrix (Dewhurst et al., 1999). Again an exponential relationship is shown for this parameter (Figure 8, right) as linear and logarithmic fits tended to zero cohesive strength at clay fractions of $\sim 50 \%$ :

$$
C=50.47 e^{-0.07 C F} \quad\left(\mathrm{R}^{2}=0.73\right)
$$

where CF is clay fraction as a percentage.

Porosity has previously been correlated to shale unconfined compressive strength (UCS) (Lashkaripour and Dusseault, 1993; Horsrud, 2001). UCS is related to cohesive strength via friction coefficient. The correlation here (Figure 9, left) is of similar exponential form to that of Horsrud (2001), such that:

$$
C=50.88 e^{-21.28 \phi} \quad\left(\mathrm{R}^{2}=0.75\right)
$$

where $\varphi$ is porosity as a fraction. In a similar vein, water content, measured by drying also has a reasonable exponential correlation with cohesive strength (Figure 9, right):

$$
C=20.74 e^{-26.41 w} \quad\left(\mathrm{R}^{2}=0.68\right)
$$

where $\mathrm{w}$ is water content as a fraction. 

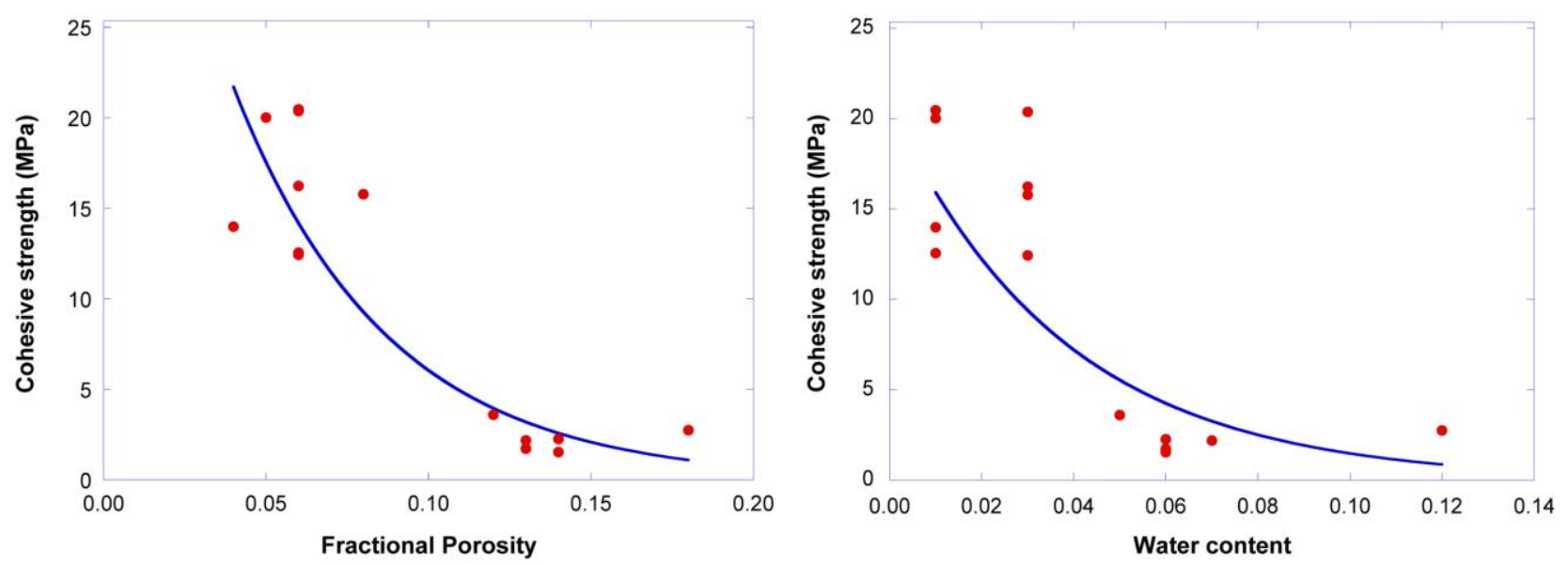

Figure 9 Plot of porosity (left) and water content (right) against measured cohesive strength for shales from the Bass, Norwegian, Officer and Carvarvon basins

The last correlation here with strength is that of cation exchange capacity (CEC) normalised to clay fraction. The reasoning behind the normalisation is that CEC is actually measured on the $<2 \mu \mathrm{m}$ fraction of the rock but strength is measured on the whole rock. Hence to realistically compare CEC data between samples with varying clay fraction, such a normalisation needs to be made but also assumes that the CEC of the $>2 \mu \mathrm{m}$ fraction is negligible. This is a reasonably good assumption as the finest grained clay minerals are those with the highest surface areas and thus CEC. The exponential correlation is shown in Figure 10 and is seemingly the best of the simple correlations to cohesive strength:

$$
C=29.65 e^{-0.24(C E C \times C F)} \quad(\mathrm{R} 2=0.83)
$$

where $\mathrm{CEC}$ is in $\mathrm{c} \mathrm{mol} / \mathrm{kg}$ and clay fraction is taken as a fraction (i.e. not in percentage).

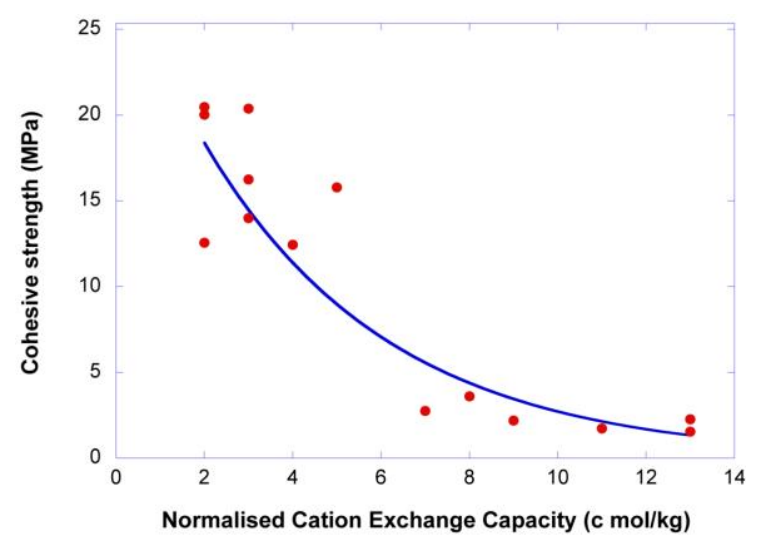

Figure 10 Plot of cation exchange capacity normalised to clay fraction against measured cohesive strength for shales from the Bass, Norwegian Sea, Officer and Carvarvon basins

One might note at this point that all these simple correlations so far suggested have been to cohesive strength and that there have been none to friction coefficient. None of the parameters investigated correlated well with friction coefficient. These include all the parameters used above to correlate with cohesive strength plus specific surface area, $\mathrm{V}_{\mathrm{p}} / \mathrm{V}_{\mathrm{s}}$ ratio and P-/S-wave anisotropy. It should also be noted that cohesive strength did not correlate with CEC alone, specific surface area, $\mathrm{V}_{\mathrm{p}} / \mathrm{V}_{\mathrm{s}}$ ratio or $\mathrm{P}-/ \mathrm{S}$-wave anisotropy. 

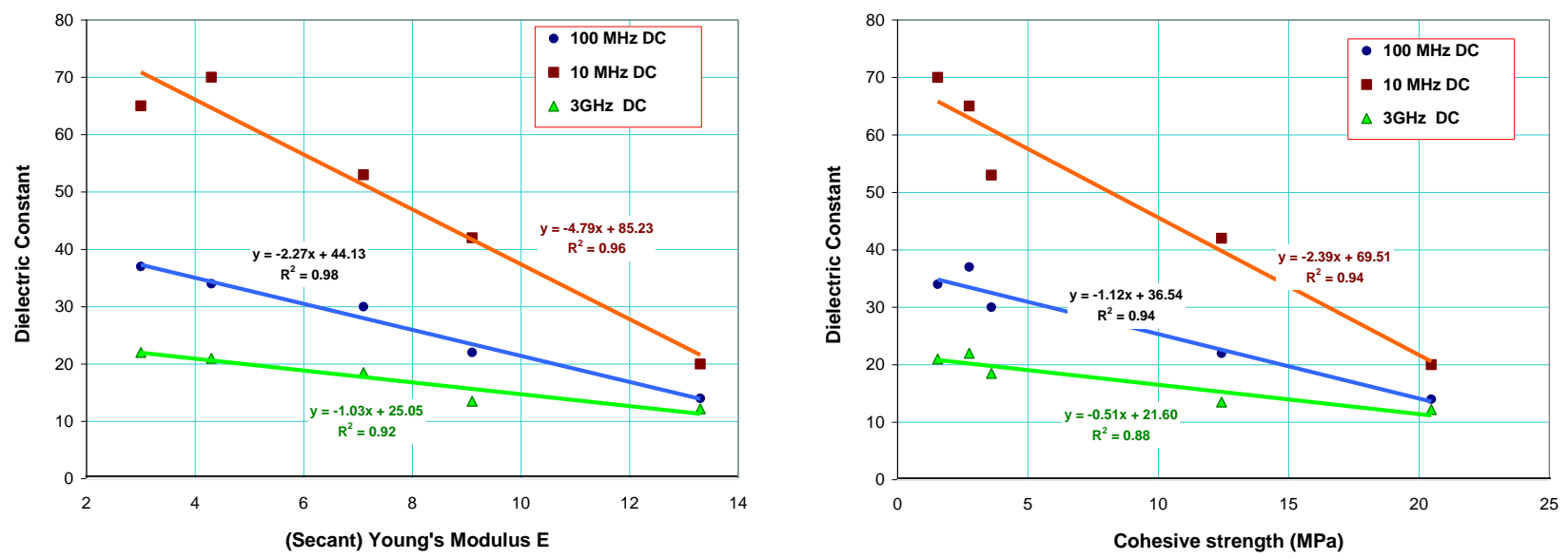

Figure 11 Relationships for dielectric constant with Young's modulus (left) and cohesive strength (right) at three different frequencies in five shale samples from the four different basins noted previously

Correlations were also made between petrophysical properties and both physical and geomechanical properties. Only five different shale samples have so far been tested. Whilst in most cases these correlations appear much better than those presented above, caution must be exercised due to the small amount of currently available data. However, we felt the correlations were notable and have considerable future potential and so have presented them here. The results discuss correlations made at three different frequencies along the dielectric sweep, namely $3 \mathrm{GHz}, 100 \mathrm{MHz}$ and $10 \mathrm{MHz}$. Two shales were analysed from the Officer Basin and one each from the Norwegian, Bass and Carnarvon basins. Excellent correlations ( $\mathrm{R}^{2}$ from 0.92-0.98) were obtained between dielectric constant and Young's modulus in the five shales tested (Figure 11). Additionally, the sensitivity appears to increase with decreasing frequency, a factor common throughout these tests. Reasonable correlations ( $\mathrm{R}^{2}$ from 0.88-0.94) were also obtained between dielectric constant and cohesive strength (Figure 11). Again, the sensitivity appears to increase with decreasing frequency.

\subsection{Rock physics response}

Rock physics measurements were made during the six triaxial deformation stages on the horizontal Norwegian shale core plug; thus the maximum principal stress direction is parallel to the shale fabric (Figure 6). $\mathrm{V}_{\mathrm{pv}}$ increases from $\sim 3300 \mathrm{~m} / \mathrm{s}$ to $\sim 3800 \mathrm{~m} / \mathrm{s}$ over the mean effective stress range measured of 10-70 MPa. It is also noticeable that within most of the individual axial stress increments, $V_{p v}$ either remains constant or falls as differential stress increases. $V_{\mathrm{ph}}$ is generally slightly higher than $\mathrm{V}_{\mathrm{pv}}$ (Figure 12), indicating slight $\mathrm{P}$-wave anisotropy and in general, within the individual axial loading stages, $\mathrm{V}_{\mathrm{ph}}$ either remains almost constant or increases. As there is little seeming P-wave anisotropy (Thomsen, 1986), it is not surprising that $\mathrm{qV}_{\mathrm{p} 45}$ is of a similar magnitude to $\mathrm{V}_{\mathrm{ph}}$ and $\mathrm{V}_{\mathrm{pv}}$.

S-wave velocity however shows more anisotropy (Thomsen, 1986) than P-wave velocity in this Norwegian shale (Figure 12). $\mathrm{V}_{\mathrm{s} 1}$ increases from $\sim 1800 \mathrm{~m} / \mathrm{s}$ to $\sim 2100 \mathrm{~m} / \mathrm{s}$ over the stress range investigated, although it decreases with increasing mean effective (and therefore differential) stress during each individual loading increment. $\mathrm{V}_{\mathrm{sh}}$ increases from $\sim 2100$ to $\sim 2300 \mathrm{~m} / \mathrm{s}$ as mean effective stress increases to $70 \mathrm{MPa}$, but within each loading increment, velocity generally increases, if only slightly. Anisotropy is also shown in Figure 12, with $\varepsilon$ being slightly scattered although this is likely due to its proximity to zero. However, $\gamma$ is moderately high $(\sim 10 \%)$ and generally decreases as confining pressure increases. It flattens off at mean effective stresses higher than $\sim 40 \mathrm{MPa}$, but increases during each individual loading cycle. 

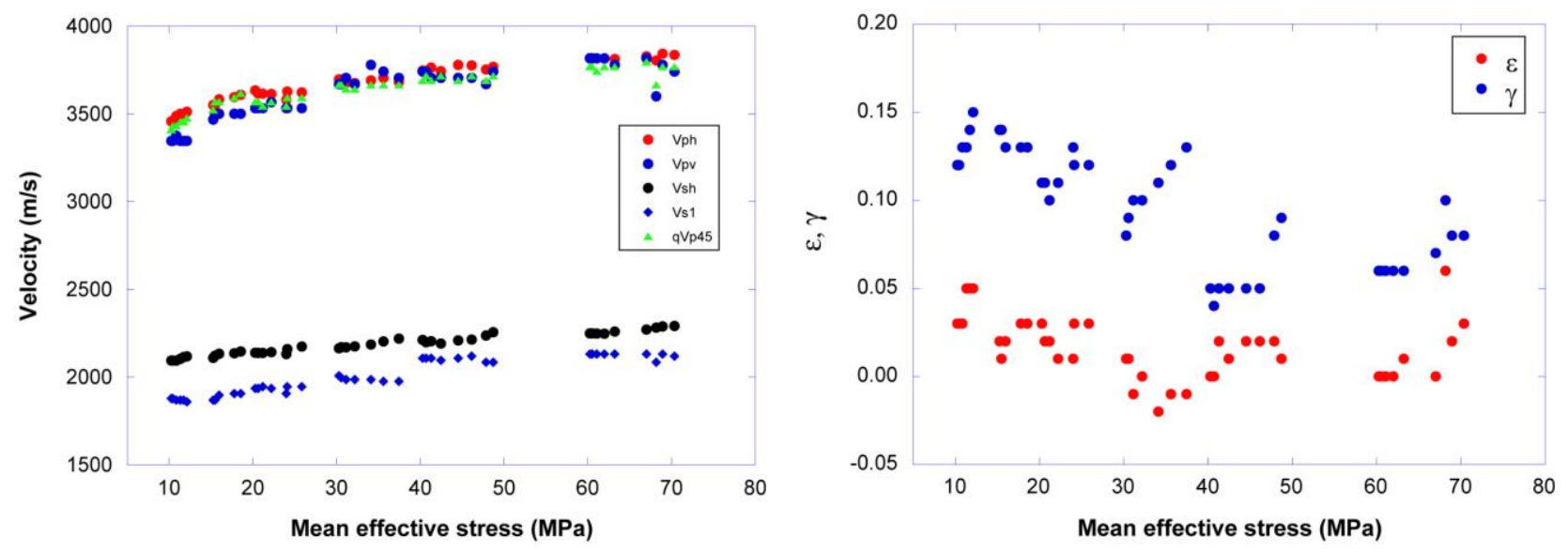

Figure 12 (Left) Velocity-mean effective stress relations for a Norwegian shale; (right) P-wave anisotropy $(\varepsilon)$ is scattered but relatively unchanged during individual loading stages with increasing mean effective stress, while $S$-wave anisotropy $(\gamma)$ decreases with application of confining pressure but increases during each loading increment

Figure 13 shows velocities recorded in an Officer Basin shale using a vertical core plug through five triaxial loading stages, i.e. the maximum principal stress is now normal to the fabric. $\mathrm{V}_{\mathrm{pv}}$ increases from $\sim 3500 \mathrm{~m} / \mathrm{s}$ to $\sim 3800 \mathrm{~m} / \mathrm{s}$ over an effective stress range of $10-80 \mathrm{MPa}$. $\mathrm{V}_{\mathrm{ph}}$ is considerably larger than $\mathrm{V}_{\mathrm{pv}}$, indicating significant $\mathrm{P}$-wave anisotropy, generally lying between $\sim 4100$ and $4400 \mathrm{~m} / \mathrm{s}$. However, $\mathrm{V}_{\mathrm{ph}}$ decreases during each individual loading stage. The quasi-P-wave velocity, $\mathrm{qV}_{\mathrm{p} 45}$, is slightly higher than $\mathrm{V}_{\mathrm{pv}}$ although lying much closer to the latter than to $V_{\mathrm{ph}}$. $\mathrm{V}_{\mathrm{s} 1}$ increases slightly, from just under $2000 \mathrm{~m} / \mathrm{s}$ at $10 \mathrm{MPa}$ to $\sim 2100 \mathrm{~m} / \mathrm{s}$ at $80 \mathrm{MPa}$ mean effective stress. Anisotropy is again evident in the $\mathrm{S}$-wave velocities, with $\mathrm{V}_{\mathrm{sh}}$ rising from $\sim 2400 \mathrm{~m} / \mathrm{s}$ to $\sim 2500 \mathrm{~m} / \mathrm{s}$ over the same stress range. Velocity anisotropy is also shown in Figure 13, with both $\varepsilon$ and $\gamma$ decreasing during individual loading stages although increasing confining pressure does not appear to reduce anisotropy significantly across the whole stress range.
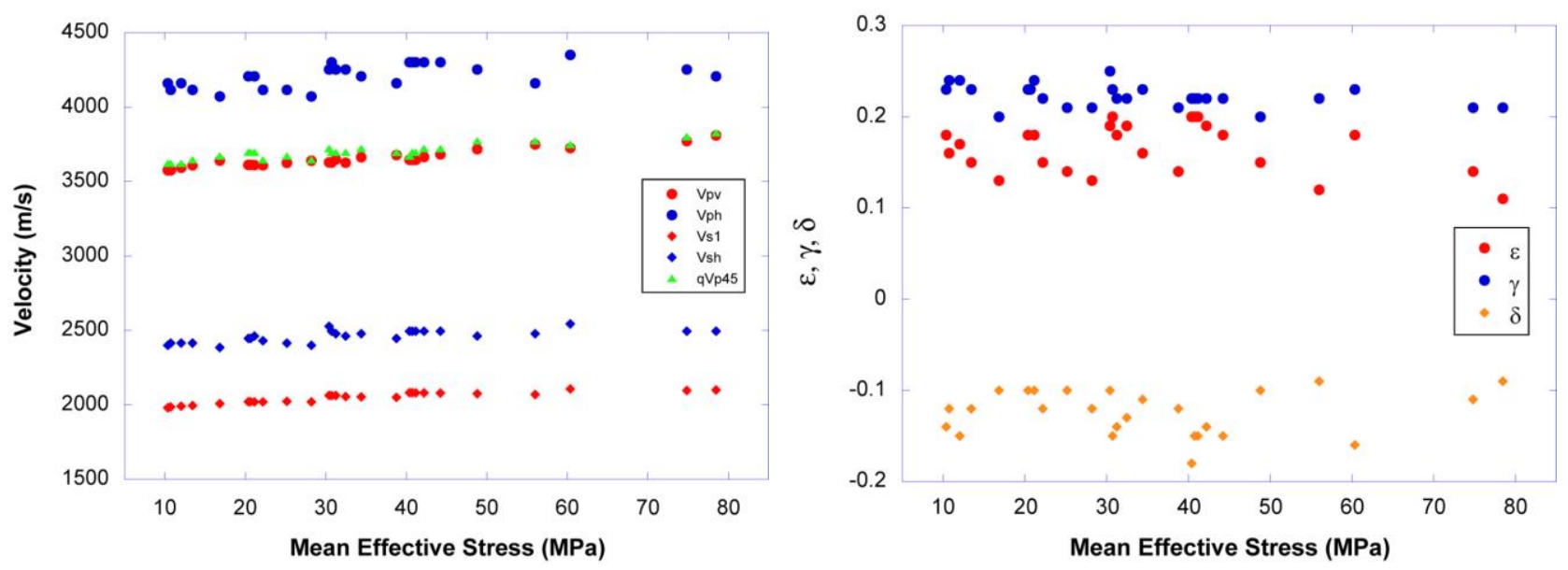

Figure 13 (Left) Velocity-mean effective stress relations for an Officer Basin shale; (right) P-wave anisotropy $(\varepsilon)$ and $S$-wave anisotropy $(\gamma)$ decrease during individual loading stages 


\section{Discussion}

\subsection{Rock physics response}

In the Norwegian shale, where the maximum principal stress is parallel to microfabric, $V_{\mathrm{ph}}$ and $\mathrm{V}_{\mathrm{sh}}$ increase with both increasing mean effective stress across the whole stress range and also within each individual test stage (Figure 12). However, while $\mathrm{V}_{\mathrm{pv}}$ and $\mathrm{V}_{\mathrm{s} 1}$ generally increase with increasing mean effective stress, within each test stage they either remain constant or decrease slightly as differential stress is applied (Figure 12). The S-wave behaviour is reflected in the $\gamma$ values measured for these samples and how $\gamma$ responds to changing differential stress. S-wave anisotropy increases within each individual loading stage as differential stress increases (Figure 12). As confining pressure increases from stage to stage, S-wave anisotropy decreases at any given differential stress up to mean effective stresses of about $40 \mathrm{MPa}$ and then becomes approximately constant. It would appear therefore that application of an isotropic stress field serves to close pre-existing cracks in the shale, which reduces S-wave anisotropy to that resulting from clay fabric alignment alone at mean effective stresses above $40 \mathrm{MPa}$. However, increasing differential stress causes $\gamma$ to increase through opening and propagation of bedding-parallel fractures which are aligned with the maximum principal stress direction (Figure 6).

In the case of the Officer Basin shale (Figure 13), the maximum principal stress is acting perpendicular to bedding (Figure 6) and has different effects on vertical and horizontal velocities. Within each cycle of loading, $\mathrm{V}_{\mathrm{pv}}$ and $\mathrm{V}_{\mathrm{s} 1}$ increase slightly or remain constant with increasing differential stress. However, $\mathrm{V}_{\mathrm{ph}}$ and $\mathrm{V}_{\text {sh }}$ remain constant initially at low axial loads but start to decrease as the load increases. Microcracks present in shales are often bedding-parallel and in these tests are oriented normal to bedding and are likely to close with increasing load. This can account for the general increase seen in $V_{p v}$ and $V_{s 1}$ and the constancy of $\mathrm{V}_{\mathrm{ph}}$ and $\mathrm{V}_{\mathrm{sh}}$ at low stress. However, continued deformation and increased differential stress tend to initiate fractures perpendicular to the minimum stress (Figure 14) (Paterson, 1978). Within individual loading cycles, vertical cracks start to open and propagate above a given differential stress level which reduces $\mathrm{V}_{\mathrm{ph}}$ and $\mathrm{V}_{\text {sh. }}$. With increasing differential stress, these fractures continue to grow and connect, eventually leading to a through going shear fracture.

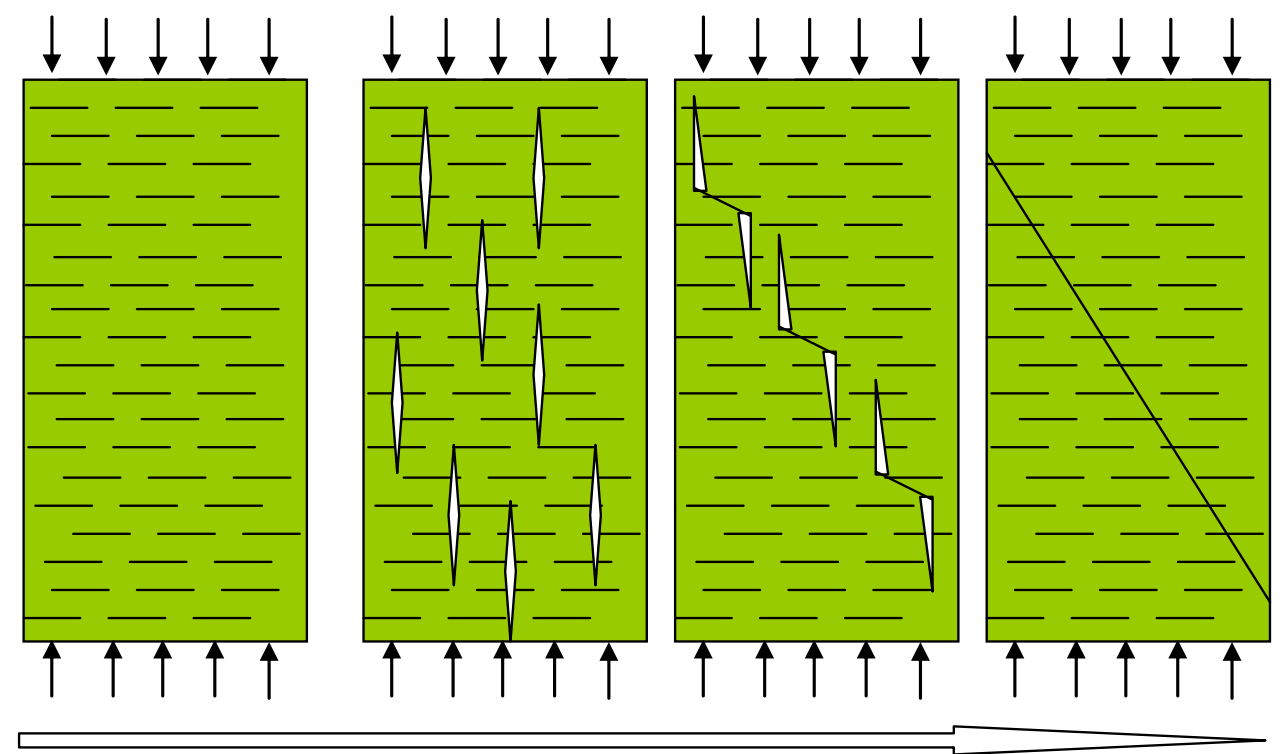

Increasing Differential Axial Load

Figure 14 Schematic model of evolution of cracks and failure in an Officer Basin shale core plug with increasing differential stress acting perpendicular to the bedding (arrows). Velocities are measured axially and radially, thus normal and parallel to fracture development in this schematic 
The contrast between the anisotropy results on core plugs deformed normal (Officer shale) and parallel (Norwegian shale) to bedding thus emphasise the importance of the fabric and structural anisotropies relative to the prevailing stress field for wave propagation in inherently anisotropic media such as shales.

\subsection{Geomechanical empirical correlations}

Some uncertainties should also be noted regarding the correlations presented above in addition to the sources of measurement error already outlined. It has been noted above that the tests run are multi-stage triaxial tests and as such, the points where individual stages are stopped (except the last point of the test) are human decisions, not exact points of failure. Hence, each point on the failure envelope except the last, slightly underestimates the actual peak strength of the material at failure. This has the effect of slightly raising the friction coefficient and slightly lowering the cohesive strength as compared to samples run in single stages, although the latter type of test can also suffer considerably through sample heterogeneity. The nature of the multi-stage test means that sample fatigue may also be an issue, which would serve to lower friction coefficients. The very linear nature of all the failure envelopes in this study $\left(\mathrm{R}^{2}>0.98\right.$ in almost all cases) tend to argue against this and samples that do fail early in a test cycle are usually obvious and have been removed from the correlations. The effects of unloading are also ignored for these samples, although it is likely minimal in these cases as most samples are low porosity, high stiffness shales which undergo a large degree of elastic deformation and much smaller amounts of plastic deformation compared to higher porosity shales. The issue was not specifically investigated in these tests though. A third issue to be aware of is that the tests were conducted at room temperature but both static and dynamic properties of shales are likely to be temperature dependent (Johnston, 1987; Horsrud et al., 1998). Finally, the question is unresolved on the nature of velocity dispersion in shales (Liu et al., 1994; Duranti and Ewy, 2006), heterogeneity and rock volume may be issues with correlation between ultrasonic laboratory measurements and wireline/LWD logging frequencies. One should also be wary of anisotropy and deviated wells in terms of using velocity (Horsrud, 2001) as the correlation presented above is specifically for impedance based on $\mathrm{V}_{\mathrm{pv}}$.

Velocity has previously been used for predicting geomechanical properties as this is a practical parameter to use in terms of wireline logs for giving continuous mechanical property logs downhole and possibly even in real time from LWD/MWD. Horsrud (2001) documented empirical correlations for shale mechanical properties noting relationships with velocity and porosity. He noted similar issues to those documented above in that unconfined compressive strength (UCS, directly related to cohesive strength through the friction coefficient) had good correlations to velocity and porosity but friction coefficient was much more difficult to relate to any parameter he measured (maximum $\mathrm{R}^{2}=0.59$, most $<0.4$ ). The major difference between Horsrud's (2001) work and the shales tested here, composition aside, is porosity. Most of his samples have $\varphi>30 \%$, with only one $<10 \%$, whereas all samples documented above have porosity $<20 \%$, with a significant number $<10 \%$. Chang et al. (2006) examined strength data on 100 shales, but unfortunately most of these were tested "dry". The only data from pore pressure controlled tests was that of Horsrud (2001) noted above. Chang et al. (2006) also note that little work has been done on correlating friction coefficient and that the few published attempts are likely to suffer from the complexity of the relationships between microstructure, micromechanics and friction coefficient.

Horsrud (2001) noted that all the shales he tested were from the North Sea Tertiary and so suggested caution when applying his empirical correlations to shales as a whole. He did note that other shales tended to fit the empirical correlations presented. The implication of the data and correlations presented above is that some reasonable correlations can be obtained (for cohesive strength) for shales from four different basins (Bass, Officer, Norwegian and Carnarvon) widely separated in space and time (Proterozoic to Tertiary).

\section{Conclusions}

We have deformed some preserved shales from the Officer, Carnarvon, Bass and Norwegian Sea basins and determined failure envelopes. Rock physics measurements comprising the full elastic tensor were also taken during undrained multi-stage triaxial testing of the Norwegian and Officer basin samples. The Norwegian shale exhibited slight P-wave anisotropy at low effective stress, decreasing to almost isotropy at high stress; it also showed moderate $\mathrm{S}$-wave anisotropy. These phenomena were associated with both a compaction fabric and microcracks. In the case of the Norwegian shale, isotropic stress fields decreased S-wave velocity anisotropy, whereas anisotropic stress fields significantly increase the observed S-wave anisotropy. In the 
Officer Basin shales, velocity normal to bedding generally increased with both increasing confining pressure (isotropic stress) and axial load (stress anisotropy). However, both P- and S-wave anisotropy were observed to decrease during individual loading stages with the application of differential stress, although isotropic stress fields alone had little effect on velocity anisotropy. The orientation of fabric elements with respect to the stress field appears critical in understanding the evolution of velocity anisotropy during rock deformation.

Simple empirical correlations of geomechanical properties to physical and petrophysical properties have been suggested for the shales we have tested so far from the Bass, Officer, Carnarvon and Norwegian Sea basins. Further additions to the dataset are required (and are currently ongoing) to cover a wider range of shale types and to increase the number of data points. A number of reasonable correlations $\left(\mathrm{R}^{2} \sim 0.8\right)$ to cohesive strength have been suggested and are of a similar form to those suggested by previous authors. So far, no good correlation of physical, petrophysical or elastic properties to friction coefficient has been found. Further thought is required as to which properties might best correlate with friction coefficient.

\section{Acknowledgements}

This research was conducted under the aegis of the IPETS Consortium sponsored by Chevron, Woodside, Origin Energy, Santos, Schlumberger, Anadarko and PIRSA, who are duly thanked for financial support and permission to publish. Significant funding was also provided by the CSIRO Wealth from Oceans Flagship research programme. Utpalendu Kuila performed some of the work in this paper while interning at CSIRO Petroleum in Perth. The preserved Norwegian shale core was kindly provided by StatoilHydro and they are duly thanked for extensive discussions of the results on this core. A suite of preserved Officer Basin shale cores were provided by the Geological Survey of Western Australia from their Lancer-1 drill hole and they are duly thanked for this kind donation. Dr. Sherry Mayo from CSIRO Materials Science and Engineering Division is thanked for the tomogram on Muderong shale.

\section{References}

Aplin, A.C., Yang, Y. and Hansen, S. (1995) Assessment of $\beta$, the compression coefficient of mudstones and its relationship with detailed lithology. Marine and Petroleum Geology, 12, pp. 955-963.

Chang, C., Zoback, M.D. and Khaksar, A. (2006) Empirical relations between rock strength and physical properties in sedimentary rocks. Journal of Petroleum Science and Engineering, 51, pp. 223-237.

Clennell, M.B., Dewhurst, D.N. and Raven, M. (2006) Shale petrophysics: electrical, dielectric and nuclear magnetic resonance studies of shales and clays. Transactions of the 47th SPWLA Annual Logging Symposium, Veracruz, Mexico, paper KK, 13 p.

Dewhurst, D.N., Aplin, A.C. and Sarda, J.P. (1999) Influence of clay fraction on pore-scale properties and hydraulic conductivity of experimentally compacted mudstones, Journal of Geophysical Research, Solid Earth, 104/B12, pp. 29261-29274.

Dewhurst, D.N. and Hennig, A. (2003) Geomechanical properties related to top seal leakage in the Carnarvon Basin, Northwest Shelf, Australia. Petroleum Geoscience, 9, pp. 255-263.

Dewhurst, D.N. and Siggins, A.F. (2006) Impact of fabric, microcracks and stress field on shale anisotropy: Geophysical Journal International, 165, pp. 135-148.

Dewhurst, D.N., Jones, R.M. and Raven, M.D. (2002) Microstructural and petrophysical characterisation of Muderong Shale: Application to top seal risking. Petroleum Geoscience, 8, pp. 371-383.

Duranti, L. and Ewy, R. (2006) Constitutive relationship for elastic anisotropy of shales: High frequency model. Abstract and presentation to FORCE conference on Seismic Imaging in Shales, Stavanger, Norway.

Holt, R.M., Fjær E., Raaen, A.M. and Ringstad, C. (1991) Influence of stress state and stress history on acoustic wave propagation in sedimentary rocks. In: Hovem, J.M., Richardson, M.D., Stoll, R.D. (editors), Shear Waves in Marine Sediments, Kluwer, The Netherlands, pp. 167-174.

Horsrud, P. (2001) Estimating mechanical properties of shale from empirical correlations. SPE Drilling and Completion, 16, pp. 68-73.

Horsrud, P., Sønstebø, E.F. and Bøe, R. (1998) Mechanical and petrophysical properties of North Sea shales. Int. J. Rock Mech. Min. Sci., 35, pp. 1009-1020.

Ingram, G.M. and Urai, J.L. (1999) Top-seal leakage through faults and fractures; the role of mudrock properties. In: Aplin, A.C., Fleet, A.J. and MacQuaker, J.H.S. (editors), Muds and Mudstones: Physical and Fluid Flow Properties, Geological Society, London, Special Publications, Vol. 158, pp. 125-135.

Johnston, D.H. (1987) Physical properties of shales at temperature and pressure. Geophysics, 52, pp. 1391-1401. 
Lashkaripour, G.R. and Dusseault, M.B. (1993) A statistical study on shale properties: Relationships among principal shale properties. In: Probabilistic Methods in Geotechnical Engineering, Li, K.S. and Lo, S-C.R. (editors), Balkema, Rotterdam, The Netherlands, pp. 195-200.

Liu, X., Vernik, L. and Nur, A. (1994) Effects of saturating fluids on seismic velocities in shales. SEG Annual Meeting Expanded Abstracts, 64, pp. 1121-1124.

Marsden, J.R., Holt, R.M., Nakken S.J. and Raaen, A.M. (1992) Mechanical and petrophysical characterisation of highly stressed mudstone. In: Hudson, J.R. (editor), Rock Characterisation, proceedings of the ISRM Conference, Europe 92, pp. 51-56.

Nygard, R. and Gutierrez, M. (2002) Undrained shear behaviour of some UK mudrocks explained by petrology. Journal of Canadian Petroleum Technology, 41, pp. 37-46.

Nygard, R., Gutierrez, M., Gautam, R. and Høeg, K. (2004) Compaction behavior of argillaceous sediments as function of diagenesis. Marine and Petroleum Geology, 21, pp. 349-362.

Paterson, M.S. (1978) Experimental Rock Deformation: The Brittle Field. Springer, Berlin, 254 p.

Steiger, R.P. and Leung, P.K. (1988) Quantitative determination of the mechanical properties of mudrocks. SPE 18024.

Thomsen, L. (1986) Weak elastic anisotropy. Geophysics, 51, pp. 1954-1966.

Vernik, L. and Liu, X. (1997) Velocity anisotropy in shales; a petrophysical study. Geophysics, 62, pp. 521-532. 